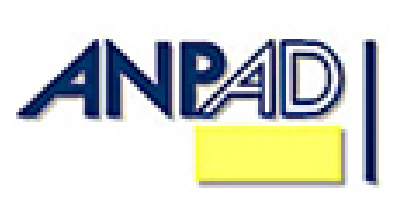

\title{
Práticas de Recursos Humanos do Processo de Repatriação de Executivos Brasileiros
}

\section{Human Resource Management Policies and Practices for Repatriation Processes of Brazilian Executives}

Mariana Barbosa Lima * M estre em A dministração de Empresas pela EA ESP/FGV. Chefe da Divisão A dministrativa do M useu Lasar Segall/IBR AM /M inc, São Paulo/SP, B rasil.

Beatriz Maria Braga Doutora em Administração pela FEA/USP. Professora A djunta da EAESP/FGV, São Paulo/SP, B rasil. citar parte de artigos sem autorização prévia desde que seja identificada a fonte. 


\title{
RESUMO
}

A repatriação é um processo de importância estratégica para as organizações internacionalizadas e a gestão desses executivos requer políticas e práticas inovadoras, dada a complexidade dos desafios que enfrentam em suas carreiras internacionais. A pesquisa sobre o tema tem sido realizada, em geral, com os repatriados, sendo poucos os estudos conduzidos com as organizações e nenhuma no contexto brasileiro. Este artigo pretende ser uma contribuição sobre o tema, ao apresentar uma pesquisa que teve por objetivo investigar e analisar as políticas e práticas adotadas por 20 multinacionais, brasileiras e estrangeiras, instaladas no B rasil, quanto ao processo de repatriação de executivos brasileiros na perspectiva da organização, representada pelo responsável pelo processo de expatriação e repatriação. Os resultados mostram que as políticas e práticas adotadas são mais voltadas a oferecer apoio operacional do que direcionadas a um plano estratégico de aproveitamento de competências e experiências. A demais, a permanência do repatriado na empresa e a adaptação do repatriado e da família ao país, à vida social e familiar, parecem depender mais do esforço pessoal dos repatriados e familiares e do próprio mercado de trabalho do país, do que das práticas organizacionais.

Palavras-chave: gestão internacional de recursos humanos; políticas e práticas de recursos humanos para repatriados; repatriação; expatriação; gestão de pessoas.

\begin{abstract}
Repatriation of executives is a process of strategic relevance for international companies and, therefore, managing these executives requires innovative policies and practices, given the complexity of the challenges they face in developing international careers. In general, research on the theme has been conducted from the viewpoint of the repatriates themselves rather than that of the organizations, and there is no record of such a study conducted in the B razilian context. In order to contribute to this field of study, the main objective of the research presented in this article was to investigate the policies and practices of the repatriation process of B razilian executives adopted by 20 B razilian and foreign multinational companies installed in B razil, as reported by the person in charge of the repatriation process. The results showed that the adopted policies and practices are more focused on offering operational support than directed to attend a clear strategic action plan that utilizes the competencies and experiences acquired by the repatriate during the expatriation period. The results also showed that whether executives remain in the company and how well they adapt to the country and to social and family life seems to depend more on their own perseverance and the country's labor market condition than on organizational practices.
\end{abstract}

Key words: international human resource management; human resource management policies and practices on repatriation; expatriation; repatriation; human resource management. 


\section{INTRODUÇÃO}

A expatriação é a transferência do executivo para trabalhar e viver em outro país, em geral acompanhado por sua família, por um período de tempo superior a um ano. 0 processo de expatriação pode ser sucedido pelo processo de repatriação do executivo, definido como o seu retorno ao país de origem, após ter cumprido seu objetivo ou contrato na organização hospedeira ou por uma nova expatriação.

Um dos desafios para as empresas é oferecer apoio a esses executivos durante os processos de expatriação e repatriação, por meio das políticas e práticas de recursos humanos, pois esse apoio contribui para a retenção e o sucesso do processo de adaptação dos executivos, tanto na ida quanto na volta, em termos profissionais, pessoais, organizacionais, sociais e culturais. Em relação à repatriação mais especificamente, a retenção dos repatriados é importante pelo al to investimento feito no processo de expatriação e, principalmente, pelas competências que esses executivos adquirem com a experiência internacional. Esses executivos passam a deter conhecimento de outras culturas e redes de relacionamentos internacionais, compreendem os negócios da empresa de maneira global e podem, no retorno, atuar como integradores e disseminadores desse conhecimento.

As pesquisas sobre o tema, em geral quantitativas, investigam a percepção dos repatriados sobre 0 processo de retorno ao país de origem. Os resultados mostram que os executivos percebem que as práticas das empresas não atendem às suas expectativas e, portanto, enfrentam muitos problemas de adaptação e frustrações (Linehan \& Scullion, 2002; Suutari \& B rewster, 2003; Tung, 1998). Poucos são os estudos que investigam o tema sob o ponto de vista da organização (Harvey, 1989; Lazarova \& Caligiuri, 2001; Lazarova \& Cerdin, 2007). Em relação à literatura nacional, não foi encontrado nenhum estudo sobre repatriados nos anais do Encontro Nacional da Associação Nacional de PósGraduação e Pesquisa em Administração [ENA NPAD] desde 0 ano de 2000 e apenas alguns artigos sobre expatriação mencionam o tema (ver Freitas, 2000a; Pereira, Pimentel, \& K ato, 2004).

Este artigo pretende ser uma contribuição ao tema ao apresentar uma pesquisa que teve por objetivo investigar e analisar as políticas e práticas adotadas por 20 multinacionais, brasileiras e estrangeiras, para o processo de repatriação de executivos brasileiros sob a perspectiva da organização, representada pelo responsável pelo processo de expatriação e repatriação. 0 artigo está estruturado da seguinte forma. A pós essa introdução, apresenta-se uma revisão teórica do tema; a seguir, a metodologia de pesquisa e os principais resultados são apresentados e discutidos; considerações finais e limitações da pesquisa se seguem.

\section{REVISÃo TEÓRICA}

0 aumento da mobilidade internacional, ocasionado pelo crescimento acelerado da internacionalização nas últimas décadas, torna fundamental para as empresas multinacionais entender os problemas relacionados à gestão internacional de recursos humanos, uma vez que os desafios em ambientes internacionais são diferentes e mais complexos (Linehan \& Scullion, 2002; Scullion, 1994; Stevens, Oddou, Furuya, \& Bird, 2006). O sucesso dos negócios internacionais depende do recrutamento de executivos qualificados e da capacidade da organização de desenvolver e reter executivos que possuam competências e práticas de negócios globais, conhecimentos de outras culturas e redes de relacionamentos internacionais (Scullion, 1994; Stevens et al., 2006).

Tem sido dito que uma das formas mais eficazes de desenvolver executivos globais é por meio da carreira internacional, em que el es podem, durante a expatriação, assumir responsabilidades, desafios e desenvolver novas competências, relacionamentos e ideias (Nunes, V asconcelos, \& J aussaud, 2008; Tung, 1998). Em geral, um executivo expatriado custa para a organização duas ou três vezes mais do 
se estivesse em uma posição equival ente no país de origem, mas esse custo pode ser percebido como investimento com retornos significativos, se a empresa utilizar, na repatriação, as competências e experiências adquiridas pelo executivo no exterior (Black \& Gregersen, 1999; Freitas, 2000a; Tung, 1998).

Os resultados de pesquisas têm mostrado que a repatriação pode ser um processo problemático para o indivíduo que a vivencia e para a organização. Os repatriados se sentem frustrados na volta e muitos deixam as organizações que, com isso, perdem valiosos colaboradores (Stahl, Chua, Caligiuri, Cerdin, $\&$ Taniguchi, 2009; W itting-B erman \& Beutell, 2009). De acordo com os resultados das pesquisas, as dificuldades enfrentadas pelos repatriados, de ordem pessoal e profissional, tendem a aumentar conforme aumenta o período de expatriação (Linehan \& Scullion, 2002).

Em termos profissionais, durante a expatriação podem ocorrer mudanças na organização de origem, como reestruturações e mudanças na estratégia organizacional. 0 indivíduo também muda durante a experiência internacional, sua identidade é redefinida, sua visão de mundo e seus valores mudam, assim como a sua família, e a cultura da organização podem não ser mais compatível com o novo indivíduo que retorna (Linehan \& Scullion, 2002; Stroh, Gregersen, \& Black, 1998; Suutari \& Brewster, 2003). 0 indivíduo sofre o que se denomina de choque cultural reverso, ou seja, sofre dificuldades de adaptação ao trabalho, a organização e à vida pessoal, associadas ao processo de repatriação (Harvey, 1989; Tung, 1988).

Ao ser expatriado, o indivíduo vivencia experiências únicas, adquire novos conhecimentos e desenvolve novas ideias e, no retorno, espera que seus conhecidos se interessem por tudo o que ele passou no exterior, o que muitas vezes não acontece. No ambiente de trabalho, o repatriado pode encontrar diversas dificuldades, como ressentimento dos colegas e a indiferença dos superiores em relação às competências e experiências adquiridas durante a expatriação (Freitas, 2000b). 0 repatriado se sente subaproveitado, o que pode afetar negativamente 0 seu bem-estar psicológico e as suas atitudes no trabalho (Black \& Gregersen, 1999; Harvey, 1989).

A lém disso, na repatriação, não estão presentes a novidade e a aventura de explorar o desconhecido, assim como na expatriação. 0 fascínio e o status social de viver uma experiência internacional não fazem parte do retorno. A demais, na volta, o executivo abre mão da autonomia e da liberdade que usufruía durante a expatriação; tem que lidar com a perda dos benefícios financeiros recebidos durante a expatriação e, al guns precisam lidar com o fato de ficar à espera de outra oportunidade de trabal ho, pois podem retornar e não haver um posto disponível na organização (Freitas, 2000a; Tanure \& Duarte, 2007).

Em termos pessoais, as pesquisas apontam outros fatores que influenciam na adaptação do repatriado: (i) a recolocação do cônjuge (em geral, a esposa) no mercado de trabal ho e a adaptação deste no retorno, que não esperava encontrar dificuldades no país de origem, como problemas dos filhos na escola e o restabelecimento da casa; (ii) a adaptação dos filhos à escola e a dificuldade em serem aceitos nos grupos sociais, principalmente no caso dos adolescentes; (iii) a perda de status social e de ganhos financeiros adquiridos durante a expatriação, ao mesmo tempo que aumentam os gastos devido à necessidade de se restabelecer no país de origem (Harvey, 1982; Lazarova \& Caligiuri, 2001; Linehan \& Scullion, 2002; N unes et al., 2008).

Estudos mostram que cerca de $25 \%$ dos expatriados se demitem ao retornar de um posto internacional, devido a problemas relacionados à reintegração ao país ou à organização e quase um terço dos repatriados demite-se nos dois anos subsequentes à repatriação (Black \& Gregersen, 1999; L ee \& Liu, 2006). Esse alto índice de demissão pode tornar outros executivos resistentes em aceitar uma designação internacional e dificultar a empresa na implementação de uma estratégia de gestão global. Além disso, representa uma perda considerável para as empresas, tanto em termos de experiência e conhecimento, como financeiramente, pois os repatriados são recursos valiosos e caros e que são capazes de entender o trabal ho tanto da organização de origem quanto das operações no exterior. E os repatriados que se demitem, em geral são empregados pelas empresas concorrentes (Lazarova \& Caligiuri, 2001; N elson, 2005). 
Dadas essas dificuldades, pesquisas têm investigado práticas que auxiliariam os executivos a desenvolverem expectativas mais realistas em relação ao seu trabalho e a sua vida particular antes da repatriação (Suutari \& B rewster, 2003). A ções das empresas em relação aos problemas citados acima podem aumentar não somente a taxa de retenção desses executivos valiosos como também os ajuda a enfrentar os desafios da adaptação no retorno ao país de origem. No entanto as pesquisas apontam que as empresas não preparam o retorno do executivo com o mesmo interesse e cuidado com que prepararam a expatriação (L inehan \& Scullion, 2002; Stroh et al., 1998; Suutari \& Brewster, 2003).

Fornecer suporte, apoio organizacional e diminuir as incertezas por meio da disponibilização de informações claras sobre a organização no país de origem, antes e durante o processo de repatriação, seriam os fatores principais para o sucesso do retorno do expatriado. Ademais, seria importante conhecer as expectativas do executivo para trabal har nos intervalos ocasionados pela distância e pelo tempo (Stroh et al., 1998; Thomas \& Lazarova, 2006). Outro fator que pode auxiliar 0 desenvolvimento de expectativas realistas é o contato com o país de origem por meio de ligações telefônicas e viagens, pois estas colocam o executivo em contato com a realidade e diminui a sensação de isolamento (L azarova \& Caligiuri, 2001).

0 treinamento antes do retorno pode facilitar a aquisição de informações e a formação de expectativas realistas. Pesquisas indicam que normalmente as organizações oferecem apenas treinamentos de natureza técnica; no entanto o treinamento deveria possibilitar ao executivo desenvolver expectativas realistas em relação ao retorno de maneira geral e auxiliá-lo na adaptação ao trabalho e ao país, trazendo aspectos relacionados ao trabalho, interação com os conterrâneos e condições gerais do país (Lazarova \& Caligiuri, 2001; L inehan \& Scullion, 2002; Suutari \& B rewster, 2003).

Os problemas familiares têm impacto na produtividade do repatriado na organização e, portanto, incluir os familiares no programa de repatriação poderia diminuir o estresse vivenciado pela família no retorno (Harvey, 1982). Esse programa deveria incluir o apoio logístico de encontrar moradia e escola para os filhos, e também o apoio psicológico para o repatriado e os familiares, principalmente no que se refere ao processo de readaptação social e cultural, especialmente para aqueles que ficaram longos períodos fora do país.

A clareza das regras da colocação internacional e do processo de repatriação também auxilia 0 desenvolvimento de expectativas realistas, dado que reduz a ambiguidade do processo. Em geral, o repatriado espera ocupar um alto cargo e espera poder utilizar as competências adquiridas durante 0 tempo no exterior e, portanto, a negociação sobre a carreira e o retorno se torna elemento essencial para o sucesso da repatriação. E caso não haja disponibilidade de um posto de trabalho para 0 executivo na volta, a empresa deveria deixar claro que forneceria um serviço de recolocação no mercado de trabalho. A lém disso, estimular 0 apoio da área e dos colegas com quem que o repatriado irá trabalhar, bem como procurar valorizar as competências adquiridas na experiência internacional facilitará não apenas a sua adaptação, mas também serão formas de disseminação de conhecimento e experiência valiosos dentro da organização (Stroh et al., 1998; Suutari \& B rewster 2003).

A disponibilidade de um mentor que acompanhe tanto a fase de expatriação como a de repatriação pode também ajudar a manter o executivo em contato com a organização. A lém disso, manter 0 vínculo com alguém da organização de origem diminui o sentimento de "estar por fora" no retorno, pois o expatriado saberá as mudanças que estão ocorrendo na empresa durante a sua ausência (Gonçalves \& M iura, 2002; Pereira et al., 2004; Suutari \& B rewster, 2003; Tung, 1988).

Como se pode observar da revisão teórica, há muito que as empresas podem fazer para garantir melhor processo de repatriação e a retenção desses executivos. As práticas sugeridas pela literatura tentam solucionar ou amenizar os problemas relatados pelas pesquisas realizadas com os próprios repatriados; mas, ao que parece, as empresas ainda estão longe de atender a essas expectativas. No Brasil, nenhuma pesquisa foi realizada sobre práticas do processo de repatriação e, portanto, este trabal ho pretende ser uma contribuição especial no setor. 


\section{METODOLOGIA}

O objetivo principal desta pesquisa é realizar um levantamento e analisar as políticas e práticas de recursos humanos adotadas por empresas brasileiras internacionalizadas e multinacionais estrangeiras estabelecidas no Brasil no processo de repatriação de executivos brasileiros expatriados.

0 estudo é de natureza descritivo-analítica, uma vez que pretende investigar um tema ainda pouco estudado na literatura acadêmica. A dotou-se uma abordagem de pesquisa qualitativa, considerada adequada para estudos de natureza exploratória (Godoi \& M attos, 2006), e a entrevista semiestruturada como método de levantamento de dados.

0 roteiro para a entrevista partiu das práticas recomendadas pela literatura para um melhor processo de repatriação de executivos e que foram utilizadas em questionários em pesquisas anteriores sobre 0 tema (Harvey, 1989; Lazarova \& Caligiuri, 2001), tais como: treinamento antes da repatriação; planejamento da carreira; garantia de cargo no retorno; mentor durante a expatriação; programa de orientação sobre as mudanças na organização durante o tempo da expatriação; seminários de treinamento de adaptação emocional após repatriação; assistência e aconsel hamento sobre mudanças no estilo de vida no retorno; comunicação contínua com o home office; sinais visíveis de valorização da experiência internacional; comunicação de detalhes da repatriação; assistência para insatisfação e desorientação da família; orientação para perda de autonomia e status; gerenciamento do stress/apoio psicológico.

Nesse sentido, procurou-se investigar se as empresas da amostra possuíam ou não essas políticas e práticas, grau de estruturação, modo de operacionalização, a existência de outras políticas e práticas e outros benefícios, assim como a percepção dos entrevistados sobre a utilização e a efetividade destas. A pesquisa é, portanto, inovadora, pois quase todos os demais estudos sobre práticas são quantitativos (Harvey, 1989; Lazarova \& Caligiuri, 2001) ou realizados com os repatriados (Stroh et al., 1998; Suutari \& B rewster, 2003), além de conduzidos em outros países.

Foram realizadas vinte entrevistas com os responsáveis pelo processo de expatriação e repatriação de executivos nas organizações. Cada entrevista durou aproximadamente uma hora. Três entrevistas foram realizadas por e-mail (B1, B 11 e M 2), quatro por tel efone (B 8, B 9, M 3 e M 7) e as demais foram realizadas pessoalmente. Dos entrevistados, 13 são mulheres e apenas dois dos entrevistados já foram expatriados.

Foram definidos dois critérios para a seleção da amostra: ter pessoas designadas como responsáveis pelos processos de expatriação e repatriação; e selecionar apenas empresas que tivessem executivos expatriados e repatriados.

0 princípio da saturação foi utilizado para a definição da amostra. A saturação ocorre quando 0 entrevistador percebe que entrevistas adicionais não contribuem com novos dados e para 0 desenvolvimento da pesquisa (Godoi \& Mattos, 2006). A amostra foi composta por onze empresas brasileiras internacionalizadas, selecionadas entre as empresas que aparecem na classificação elaborada pela Fundação Dom Cabral [FDC], que lista as trinta e duas empresas brasileiras mais internacionalizadas, e nove empresas multinacionais de capital estrangeiro, selecionadas entre as empresas que aparecem na revista Exame, listadas entre as 500 mel hores e maiores empresas do país, em 2008 (Editora A bril, 2008).

Os setores de atividade das empresas que participaram da pesquisa são bastante diversificados: químico, construção, cosméticos, celulose e papel, aeronáutica, eletromecânica, petroquímica, máquinas e equipamentos, alimentício, farmacêutico, consultoria, financeiro, automobilístico, telefonia celular e pneus. Todas as empresas da amostra são consideradas de grande porte. Para determinação do porte da empresa, considerou-se como empresa de grande porte aquelas com mais de 1.500 funcionários (Costa, 2008). 
A análise de conteúdo foi utilizada para interpretação dos dados obtidos. Foram utilizados dois níveis de análise. Primeiramente foi realizada uma análise de conteúdo clássica, em que a frequência de temas que surgiram nas entrevistas foi destacada. Essa técnica possibilitou que, a partir da frequência dos temas encontrados, fossem encontradas as similaridades entre as entrevistas, para sintetizar a totalidade dos dados da amostra. Em seguida, buscou-se analisar a singularidade das entrevistas, buscando-se identificar as singularidades que poderiam também contribuir para a pesquisa, mesmo que não representassem toda ou a maior parte da amostra (Bardin, 2008).

Quanto às limitações desta pesquisa, deve-se mencionar a realização de algumas entrevistas por email, pois as entrevistas realizadas pessoalmente ou por telefone apresentaram respostas mais detal hadas e permitiram que 0 assunto fosse discutido de maneira mais aprofundada. O utra limitação a ser considerada seria a relutância por parte do entrevistado em relatar os problemas, dificuldades e negligências da área pela qual é responsável.

\section{APRESENTAÇÃO DOS RESULTADOS}

Os resultados encontrados na pesquisa foram sintetizados na Tabela 1. Outras práticas surgiram al ém das utilizadas por Harvey (1989) e Lazarova e Caligiuri (2001). A ssim, para facilitar a análise dos dados, foram agrupadas em categorias de acordo com a sua natureza e função que desempenham, como, por exemplo, comunicação, treinamento, planejamento de carreira etc. Pode ser observado que algumas dessas categorias correspondem a funções tradicionais da área de Gestão de Pessoas. V ale ressaltar, no entanto, que a literatura internacional fala apenas de práticas. Para facilitar a visualização, foram assinaladas apenas as ocorrências positivas das práticas em cada empresa. A Tabela 1 mostra também os totais por empresa e por prática adotada. A seguir, os resultados são apresentados. 
Tabela 1

\section{C aracterísticas da Entrevista e da Organização}

\begin{tabular}{|c|c|c|c|c|c|c|c|c|c|c|c|c|c|c|c|c|c|c|c|c|c|c|}
\hline \multirow[b]{2}{*}{ Categorias } & \multirow[b]{2}{*}{ Práticas } & \multicolumn{11}{|c|}{ E mpresas B rasileiras } & \multicolumn{9}{|c|}{ E mpresas M ultinacionais } & \multirow[b]{2}{*}{ Total } \\
\hline & & B1 & B2 & B3 & B4 & B5 & B6 & B7 & B8 & B9 & B10 & B11 & M 1 & M2 & M3 & M4 & M5 & M 6 & M7 & M 8 & M9 & \\
\hline \multirow[t]{11}{*}{ Comunicação } & $\frac{\text { Comunicação }}{\frac{\text { com a }}{\text { organização: }}}$ & & & & & & & & & & & & & & & & & & & & & \\
\hline & a) Email & $\mathrm{S}$ & & & & & $\mathrm{S}$ & $\mathrm{S}$ & $\mathrm{S}$ & & & $\mathrm{S}$ & & & & & $\mathrm{S}$ & $\mathrm{S}$ & & & & 7 \\
\hline & $\begin{array}{l}\text { b) W eb } \\
\text { M essenger }\end{array}$ & $\mathrm{S}$ & & & & & & & & & & & & & & & & & & & & 1 \\
\hline & c) N ewsl etter & $\mathrm{S}$ & & & & & & & & & & & & & & & & & & & & 1 \\
\hline & d) Tel efonemas & $\mathrm{S}$ & & & & & & & & & & & & & & & $\mathrm{S}$ & $\mathrm{S}$ & & & & 3 \\
\hline & $\begin{array}{l}\text { e) Conference } \\
\text { Call }\end{array}$ & $\mathrm{S}$ & & & & & & & & & $\mathrm{S}$ & & & & & & & & & & & 2 \\
\hline & $\begin{array}{l}\text { f) Reuniões no } \\
\text { Brasil }\end{array}$ & & & $\mathrm{S}$ & $\mathrm{S}$ & & $\mathrm{S}$ & & & & $\mathrm{S}$ & & & & & & & & & & & 4 \\
\hline & $\begin{array}{l}\text { g) Portal de } \\
\text { notícias }\end{array}$ & & $\mathrm{S}$ & & & & & & & & & & & & & & & & & & & 1 \\
\hline & h) Intranet & & & & & & & $\mathrm{S}$ & $\mathrm{S}$ & & $\mathrm{S}$ & & & & & $\mathrm{S}$ & & & & & $\mathrm{S}$ & 5 \\
\hline & $\begin{array}{l}\text { i) M ailing list } \\
\text { do B rasil }\end{array}$ & & & & & & & & & & & & & & & & & & $\mathrm{S}$ & & & 1 \\
\hline & $\begin{array}{l}\text { j) M ailing } \\
\text { específico para } \\
\text { expatriados }\end{array}$ & & & & $\mathrm{S}$ & & & & & & & & & & & & & & & & & 1 \\
\hline
\end{tabular}




\section{Tabela 1 (continuação)}

\begin{tabular}{|c|c|c|c|c|c|c|c|c|c|c|c|c|c|c|c|c|c|c|c|c|c|c|}
\hline \multirow[b]{2}{*}{ Categorias } & \multirow[b]{2}{*}{ Práticas } & \multicolumn{11}{|c|}{ E mpresas B rasileiras } & \multicolumn{9}{|c|}{ E mpresas M ultinacionais } & \multirow[b]{2}{*}{ Total } \\
\hline & & B1 & B2 & B3 & B4 & B5 & B6 & B7 & B8 & B9 & B10 & B11 & M1 & M2 & M3 & M4 & M5 & M6 & M7 & M 8 & M9 & \\
\hline \multirow[t]{8}{*}{ Comunicação } & $\begin{array}{l}\text { k) V iagens do } \\
\text { responsável } \\
\text { pelos } \\
\text { expatriados aos } \\
\text { países de } \\
\text { destino das } \\
\text { expátriações }\end{array}$ & & & & & & S & & & & & & & & & & & & & & & 1 \\
\hline & $\begin{array}{l}\text { l) Comunicação } \\
\text { corporativa }\end{array}$ & & & & & S & & & & & & & & & & & & & & & & 1 \\
\hline & $\begin{array}{l}\text { m) Revista } \\
\text { Corporativa }\end{array}$ & & & & & & & & & & & $\mathrm{S}$ & $\mathrm{S}$ & & $\mathrm{S}$ & & & & $\mathrm{S}$ & & & 4 \\
\hline & $\begin{array}{l}\text { n) Boletins } \\
\text { corporativos }\end{array}$ & & & & & & & & & & & S & & & & & & & & & & 1 \\
\hline & Outros contatos: & & & & & & & & & & & & & & & & & & & & & \\
\hline & $\begin{array}{l}\text { a) Pagamento } \\
\text { de viagens }\end{array}$ & $\mathrm{s}$ & S & & & S & S & S & S & & & S & S & S & & & S & S & & S & & 12 \\
\hline & $\begin{array}{l}\text { b) Pagamentos } \\
\text { de viagens a } \\
\text { outros lugares } \\
\text { a escolha }\end{array}$ & & & $\mathrm{s}$ & S & & & & & $\mathrm{S}$ & S & & & & S & S & & & S & & S & 8 \\
\hline & $\begin{array}{l}\text { c) Pagamento } \\
\text { de ligações } \\
\text { telefônicas } \\
\text { realizadas da } \\
\text { residência }\end{array}$ & & $\mathrm{s}$ & & & & & & & & & & & & & & & & & & & 1 \\
\hline
\end{tabular}


Tabela 1 (continuação)

\begin{tabular}{|c|c|c|c|c|c|c|c|c|c|c|c|c|c|c|c|c|c|c|c|c|c|c|}
\hline \multirow[b]{2}{*}{ Categorias } & \multirow[b]{2}{*}{ Práticas } & \multicolumn{11}{|c|}{ E mpresas Brasileiras } & \multicolumn{9}{|c|}{ E mpresas M ultinacionais } & \multirow[b]{2}{*}{ Total } \\
\hline & & B1 & B2 & B3 & B4 & B5 & B6 & B 7 & B8 & B9 & B10 & B11 & M1 & M2 & M3 & M4 & M5 & M 6 & M7 & M 8 & M9 & \\
\hline \multirow{2}{*}{$\begin{array}{l}\text { Clareza e } \\
\text { estruturação } \\
\text { das regras }\end{array}$} & $\begin{array}{l}\text { No processo de } \\
\text { expatriação }\end{array}$ & $\mathrm{S}$ & $\mathrm{S}$ & $\mathrm{S}$ & $\mathrm{S}$ & $\mathrm{S}$ & $\mathrm{S}$ & $\mathrm{S}$ & $\mathrm{S}$ & $\mathrm{S}$ & $\mathrm{S}$ & $\mathrm{S}$ & $\mathrm{S}$ & $\mathrm{S}$ & $\mathrm{S}$ & $\mathrm{S}$ & $\mathrm{S}$ & $\mathrm{S}$ & $\mathrm{S}$ & $\mathrm{S}$ & $\mathrm{S}$ & 20 \\
\hline & $\begin{array}{l}\text { No processo de } \\
\text { repatriação }\end{array}$ & & & & & & & & & & & & & & & & & & & & & 0 \\
\hline \multirow[t]{2}{*}{$\begin{array}{l}\text { Treinamento } \\
\text { intercultural }\end{array}$} & $\begin{array}{l}\text { A ntes da } \\
\text { expatriação }\end{array}$ & $\mathrm{S}$ & $\mathrm{S}$ & $\mathrm{S}$ & $\mathrm{S}$ & $\mathrm{S}$ & $\mathrm{S}$ & $\mathrm{S}$ & $\mathrm{S}$ & $\mathrm{S}$ & $\mathrm{S}$ & $\mathrm{S}$ & $\mathrm{S}$ & $\mathrm{S}$ & $\mathrm{S}$ & $\mathrm{S}$ & $\mathrm{S}$ & $\mathrm{S}$ & $\mathrm{S}$ & $\mathrm{S}$ & $\mathrm{S}$ & 20 \\
\hline & $\begin{array}{l}\text { A ntes da } \\
\text { repatriação }\end{array}$ & & & $\mathrm{S}$ & & $\mathrm{S}$ & $\mathrm{S}$ & & & & & & $\mathrm{S}$ & & & $\mathrm{S}$ & & & & & $\mathrm{S}$ & 6 \\
\hline \multirow[t]{5}{*}{$\begin{array}{l}\text { Planejamento } \\
\text { da carreira }\end{array}$} & $\begin{array}{l}\text { Planejamento } \\
\text { formal da } \\
\text { carreira e do } \\
\text { retorno }\end{array}$ & $S$ & & & & & & & $\mathrm{~S}$ & & & $S$ & $S$ & & & $S$ & $S$ & $S$ & $\mathrm{~S}$ & $\mathrm{~S}$ & & 8 \\
\hline & $\begin{array}{l}\text { A proveitamento } \\
\text { das competências } \\
\text { e transmissão dos } \\
\text { conhecimentos } \\
\text { adquiridos no } \\
\text { retorno }\end{array}$ & & & & & & & & $\mathrm{S}$ & & & & & $\mathrm{S}$ & $S$ & & $S$ & & $\mathrm{~S}$ & & & 5 \\
\hline & $\begin{array}{l}\text { Garantia de } \\
\text { cargo no retorno }\end{array}$ & $\mathrm{S}$ & & & & & & & & & & & & & & $S$ & & & & & & 2 \\
\hline & $\begin{array}{l}\text { Promoção no } \\
\text { retorno }\end{array}$ & & & & & & $\mathrm{S}$ & & & & & & & & & & $\mathrm{S}$ & $\mathrm{S}$ & & & & 3 \\
\hline & $\begin{array}{l}\text { Outplacement } \\
\text { caso não haja } \\
\text { posição na } \\
\text { empresa }\end{array}$ & $\mathrm{S}$ & & & $\mathrm{S}$ & $S$ & & & & & $S$ & & & $\mathrm{~S}$ & $S$ & $\mathrm{~S}$ & & & $\mathrm{~S}$ & & & 8 \\
\hline
\end{tabular}

Continua 
T abela 1 (continuação)

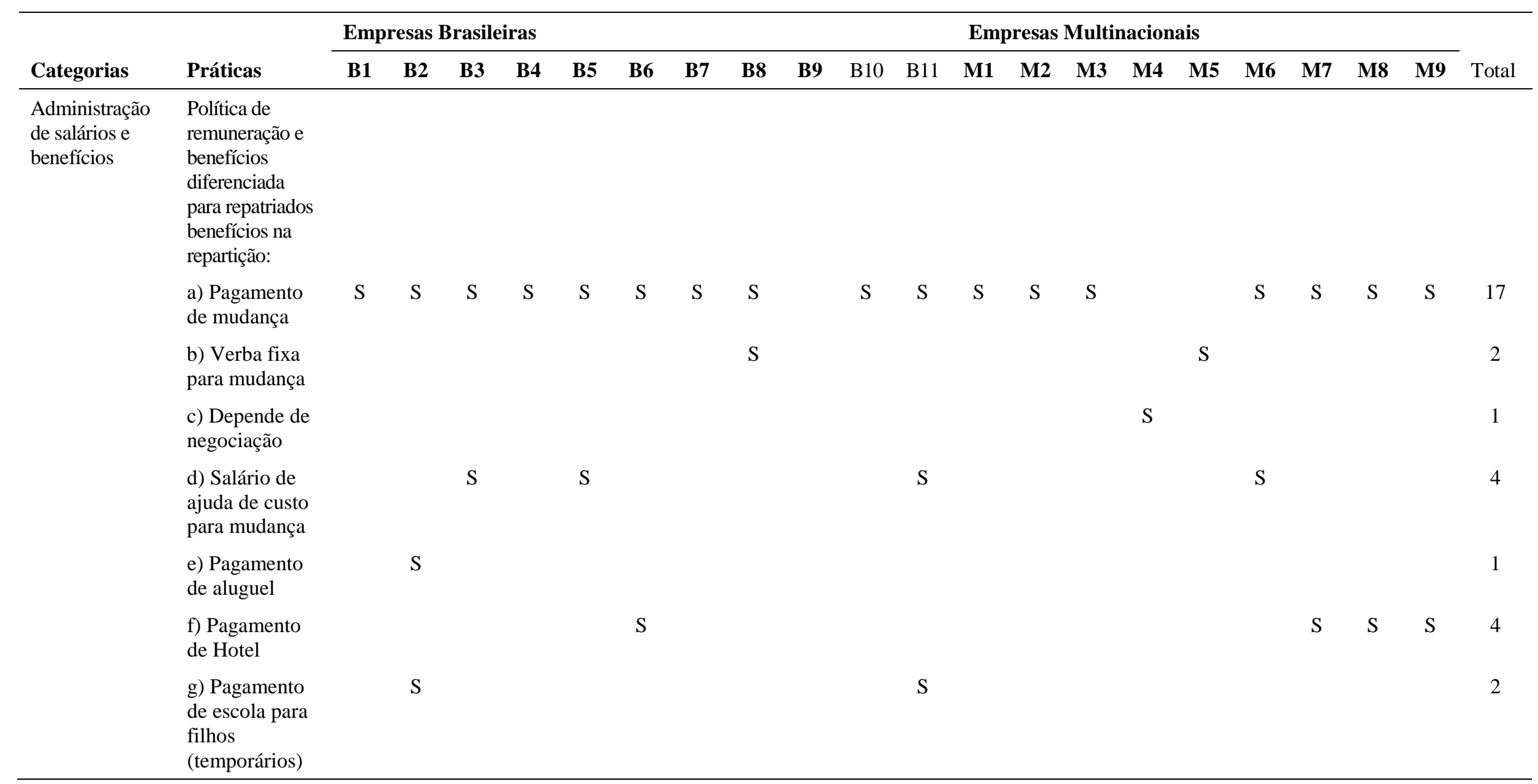


T abela 1 (continuação)

\begin{tabular}{|c|c|c|c|c|c|c|c|c|c|c|c|c|c|c|c|c|c|c|c|c|c|c|}
\hline \multirow[b]{2}{*}{ C ategorias } & \multirow[b]{2}{*}{ Práticas } & \multicolumn{11}{|c|}{ E mpresas Brasileiras } & \multicolumn{9}{|c|}{ E mpresas M ultinacionais } & \multirow[b]{2}{*}{ Total } \\
\hline & & B1 & B2 & B3 & B4 & B5 & B 6 & B7 & B8 & B9 & B10 & B11 & M 1 & M 2 & M3 & M4 & M5 & M 6 & M 7 & M 8 & M9 & \\
\hline \multirow[t]{5}{*}{$\begin{array}{l}\text { A dministração } \\
\text { de salários e } \\
\text { benefícios }\end{array}$} & $\begin{array}{l}\text { h) Pagamento } \\
\text { de aulas de } \\
\text { reforço para os } \\
\text { filhos } \\
\text { (temporário) }\end{array}$ & & & & & & & & & & & & & & & & & & & $\mathrm{S}$ & & 1 \\
\hline & $\begin{array}{l}\text { i) Pagamento } \\
\text { de aulas de } \\
\text { português para } \\
\text { os filhos não } \\
\text { alfabetizados } \\
\text { no B rasil }\end{array}$ & & & & & & $\mathrm{S}$ & & & & & & & & & & & & & & & 1 \\
\hline & $\begin{array}{l}\text { j) A uxilio } \\
\text { moradia }\end{array}$ & & & & & & & & & & & $\mathrm{S}$ & & & & & & & & & & 1 \\
\hline & $\begin{array}{l}\text { k) Serviço de } \\
\text { relocation }\end{array}$ & & & & & & & & & & & & & & & & & & $\mathrm{S}$ & $\mathrm{S}$ & & 2 \\
\hline & i) Carro & & & & & & & & & & & & & & & & & & & $\mathrm{S}$ & & 1 \\
\hline \multirow[t]{2}{*}{ A poio } & $\begin{array}{l}\text { M anutenção de } \\
\text { contato } \\
\text { constante com } \\
\text { o executivo } \\
\text { durante a } \\
\text { expatriação: }\end{array}$ & & & & & & & & & & & & & & & & & & & & & \\
\hline & $\begin{array}{l}\text { a) Responsável } \\
\text { pelo processo } \\
\text { de expatriação } \\
\text { e repatriação }\end{array}$ & $\mathrm{S}$ & & & & & $\mathrm{S}$ & $\mathrm{S}$ & $\mathrm{S}$ & & $\mathrm{S}$ & & & & & $\mathrm{S}$ & $\mathrm{S}$ & $\mathrm{S}$ & & & $\mathrm{S}$ & 9 \\
\hline
\end{tabular}




\section{Tabela 1 (continuação)}

\begin{tabular}{|c|c|c|c|c|c|c|c|c|c|c|c|c|c|c|c|c|c|c|c|c|c|c|}
\hline \multirow[b]{2}{*}{ Categorias } & \multirow[b]{2}{*}{ Práticas } & \multicolumn{11}{|c|}{ E mpresas Brasileiras } & \multicolumn{9}{|c|}{ E mpresas M ultinacionais } & \multirow[b]{2}{*}{ Total } \\
\hline & & B1 & B2 & B 3 & B4 & B5 & B6 & B7 & B8 & B9 & B10 & B11 & M 1 & M 2 & M3 & M4 & M5 & M 6 & M 7 & M 8 & M9 & \\
\hline \multirow[t]{2}{*}{ A poio } & b) Gestor & & & & & & & & & & & & & & & & $S$ & $S$ & & & & 2 \\
\hline & $\begin{array}{l}\text { d) Comitê de } \\
\mathrm{RH} \\
\text { internacional }\end{array}$ & & & & & & & & $\mathrm{S}$ & & & & & & & & & & & & & 1 \\
\hline Total & & 14 & 8 & 7 & 8 & 8 & 21 & 13 & 16 & 12 & 14 & 22 & 13 & 12 & 12 & 15 & 22 & 22 & 21 & 22 & 8 & \\
\hline
\end{tabular}

Nota. Entrevistado ex-expatriado: EB 11, EM 1; Entrevistado do sexo feminino: EB5, EB6, EB7, EB 10, EB 11 EM 1, EM 2, EM 3, EM 4, EM 5, EM 7, EM 8, EM 9; Á rea específica de expatriação e repatriação EB5, EB6, EB 7, EB 9, EM 2, EM 3, EM 4, EM 6, EM 8, EM 9; № de expatriados: até 30 expatriados: EB4, EB6, EB 10, EM 5, EM 9, EB 1, EM 4; entre 30 e 100 expatriados: EB3, EB8, EM 1, EB5, EM 7, EM 2, EM 3 e mais de 100 expatriados: EB2, EB7, EB 9, EB 11, EM 6, EM 8. 
Das onze empresas brasileiras internacionalizadas, apenas quatro possuem uma área destinada especificamente ao processo de expatriação e repatriação. Nas demais, esse processo é responsabilidade de alguma outra área, em geral a de remuneração. As empresas que possuem maior número de funcionários expatriados não são, necessariamente, as que possuem uma área específica para o processo, o que é mostrado na Tabela 1 . Em relação às empresas multinacionais de capital estrangeiro, das nove empresas da amostra, seis possuem uma área responsável especificamente pela expatriação e repatriação, independentemente do número de expatriados da empresa.

Em diversas entrevistas realizadas, ao se perguntar sobre a repatriação de executivos, os entrevistados continuaram falando sobre a expatriação, e então era necessário explicar que se desejava saber sobre o retorno dos expatriados. Nas entrevistas por e-mail, muitas perguntas sobre a repatriação foram respondidas como se fossem sobre expatriação. Percebe-se, portanto, que os termos repatriado/repatriação não fazem parte do vocabulário cotidiano de muitas empresas e que não está na mente dos entrevistados como a expatriação.

Poucas empresas souberam responder sobre o número de repatriados que possuem atualmente ou quanto recebem por ano, embora a maioria dos entrevistados soubesse exatamente o número de brasileiros expatriados: 1/3 das empresas possuem até 30; 1/3, entre 30 e 100; e outro terço, mais de 100. A Tabela 1 mostra quais são as empresas.

A nal isando-se a Tabela 1, pode-se observar o que se explicita em seguida.

Não há indícios de diferenças significativas no processo de repatriação para as empresas em que 0 responsável é um ex-expatriado e para aquelas em que as entrevistas foram realizadas por email ou por tel efone (vale ressaltar o número reduzido dessas ocorrências que dificilmente poderiam indicar alguma tendência).

- Também não há indícios de diferenças significativas no processo para as empresas em que o responsável pelo processo é mulher.

Não há indícios de diferenças também para as empresas que tem uma área específica para cuidar do processo, o que não era esperado, pois seria de supor que quando há uma área especialmente designada para cuidar de expatriação e repatriação, esses processos seriam mais bem atendidos.

- Há indicações de que o número de expatriados possa influir no tratamento dado ao expatriado, pois das 7 empresas com menos de 30 expatriados, 4 estão entre que têm mais práticas no processo (10 ou mais); das 7 que têm entre 30 e 100, apenas 2; e das 6 que têm mais de 100 expatriados, também apenas 2; portanto, pode-se supor que quando há um menor número de expatriados, há maior disponibilidade de tempo para se cuidar mais pessoalmente de cada um e de se elaborar melhores práticas para o processo.

A seguir, são apresentados os resultados das entrevistas da pesquisa sobre as práticas utilizadas.

\section{Comunicação}

Os entrevistados relataram que os expatriados são informados sobre as mudanças que acontecem na empresa do país de origem durante a expatriação, pois reconhecem que esse é um fator importante para que os expatriados não se sintam abandonados e evita surpresas do executivo na repatriação. $M$ as, conforme mostra a Tabela 1, as formas mais frequentes de comunicação com os expatriados são os emails, seguidos pela intranet e reuniões no Brasil e conference calls, meios bem menos utilizados. A penas três empresas mantêm um canal de comunicação específico com o expatriado, em que as áreas responsáveis pelos expatriados adotam uma postura ativa e têm ações como tel efonar periodicamente aos expatriados para saber sobre sua adaptação; e em apenas uma o responsável pela área de expatriados viaja até os países que a empresa possui expatriados para acompanhá-los de forma mais próxima. 
Os executivos podem ligar para o B rasil da empresa sem qualquer custo. No entanto, as ligações realizadas da residência não são pagas pela empresa. Quanto a viagens, 12 das empresas pagam viagens especificamente para o Brasil, outras empresas pagam viagens para a localidade escolhida pelo executivo, e não necessariamente para o B rasil.

Os entrevistados afirmaram que as empresas possuem as políticas de expatriação estruturadas e documentadas, mas que, em geral, esse documento não é divulgado aos funcionários. Em algumas empresas, embora existam regras, há espaço para que os benefícios sejam negociados caso a caso, antes da expatriação. Entretanto, em relação ao processo de repatriação, observou-se que, por não haver políticas estruturadas nem documentadas, as regras são pouco claras e as condições do retorno negociadas caso a caso, o que pode deixar margem a expectativas frustradas por parte dos repatriados.

Todas as empresas da amostra fornecem treinamento e orientação tanto em termos profissionais como pessoais e culturais, antes da expatriação. No entanto o tratamento é bem diferente no retorno. Em uma delas, há um treinamento, que engloba os aspectos profissionais, pessoais e culturais da repatriação. Em outra, o treinamento inclui a vida profissional e ambas têm como objetivo diminuir 0 choque cultural no retorno. N estas duas empresas, o cônjuge é incluído no treinamento, mas os filhos não, pois foi alegado que, em geral, os filhos são pequenos e não conseguem acompanhá-lo. Outras quatro empresas da amostra oferecem um treinamento que orienta os repatriados sobre as mudanças ocorridas na empresa em relação a plano de saúde, vale refeição, plano de previdência etc. No entanto reconhecem que melhor treinamento seria importante:

“Não, isso infelizmente não existe. Eu até entendo que é uma prática bem interessante, para repatriação principalmente para os postos em que a expatriação é mais longa, eles até precisariam; mas hoje não existe nada nesse sentido para os nossos funcionários" (M 7).

“Nós não damos, aquele curso que damos aos estrangeiros nós não damos aos brasileiros quando voltam. A gente percebe que é muito mais difícil readaptar do que se adaptar, quando vão para a expatriação; mas eles têm que se virar sozinhos nesse ponto" (M 3).

\section{Planejamento da Carreira}

A pesar dos entrevistados reconhecerem a importância do planejamento da carreira, 12 das empresas da amostra não têm planejamento da carreira do expatriado e a maioria (15) não tem programa específico que busque um cargo apropriado para o repatriado, em que ele utilize as competências, experiências, conhecimentos e redes de contatos adquiridos no exterior. Nove entrevistados mencionaram que a preocupação existe; mas que isso nem sempre é possível, o que parece ser justificado pela dificuldade de fazer previsões, dado que a empresa sofre mudanças constantes.

“Não tem. Planos de carreira formal, não. V ocê tem algumas linhas de pensamento, mas não é nada formal, não é um plano de sucessão" (B 4).

"então ele vai para lá, ele saiu daqui, outro teve que tomar o lugar dele, quando ele volta .... e aí faz um servicinho aqui, um servicinho ali, até que chega uma hora que ele pode perder o emprego dele" (B 10).

$V$ ale ressaltar, no entanto, que em quatro das empresas multinacionais estrangeiras, o planejamento da carreira é mais estruturado, especialmente quando o executivo está em processo sucessório. N esses casos, há uma discussão anual com os gestores para planejar o retorno do expatriado, embora não haja garantia de que haverá uma promoção ou de que assumirá um posto que Ihe permitirá utilizar as competências e experiências adquiridas durante a expatriação.

Dois entrevistados relataram que as empresas garantem um cargo no retorno, ainda que possa não ser aquele de que o repatriado gostaria e outros três afirmaram que, em geral, há uma promoção (dois destes são das multinacionais estrangeiras que têm processos sucessórios para os expatriados). E oito dos entrevistados relataram que as empresas possuem uma política de recolocação do executivo no mercado de trabal ho no caso de não haver um posto adequado para ele no retorno. 
A lém disso, os entrevistados relataram que os executivos pensam a expatriação como forma de ganhar dinheiro e que, em geral, não percebem a vivência internacional como experiência que possibilita o desenvolvimento da carreira. E isso também parecia justificar, em parte, a ausência do planejamento da carreira, ou seja, parece haver um pensamento de que a mera oportunidade de viver e trabalhar em outro país e ganhar um salário maior e mais benefícios, já seriam motivos suficientes para motivar as pessoas a uma expatriação.

\section{Administração de Salários e Benefícios}

Todos os entrevistados afirmaram que os repatriados perdem os benefícios que possuíam durante a expatriação; no retorno, a política salarial do repatriado passa a ser a do Brasil, ou seja, não há uma política que tenha como objetivo retê-los na empresa por meio do pagamento de salários e benefícios diferenciados, que valorize a experiência internacional. A inda de acordo com os entrevistados, a perda do padrão de vida que o executivo possuía durante a expatriação é um dos maiores problemas enfrentados pelos repatriados e que pode ser ainda mais sentido pela família.

A maioria (16) das empresas paga total ou parcialmente a mudança marítima ou terrestre. E quatro empresas disponibilizam ainda uma verba complementar para as despesas iniciais após a mudança.

\section{Apoio Pessoal e Familiar}

Os entrevistados reconhecem a importância da manutenção da comunicação próxima do responsável pelo processo de expatriação e repatriação, dos gestores e dos colegas da área em que trabal hava no Brasil com o executivo, que assim sente que a empresa se preocupa com o seu bem-estar e que está disposta a auxiliá-lo na resolução dos seus problemas, o que tem um impacto positivo no momento da repatriação. No entanto, apontam que como não há um planejamento para a volta do expatriado, em termos de posto de trabalho, o contato com o gestor fica bastante distanciado. 0 contato com 0 responsável pelo processo de expatriação e repatriação é mais frequente, a ponto de alguns comentarem que o expatriado se torna muito dependente e que a diversidade de necessidades é muito grande, o que torna o trabalho do responsável muito complicado.

As entrevistas mostram que há uma dificuldade em ser aceito pelos colegas, o que se deve ao fato de os colegas de trabalho não estarem preparados para receber o repatriado. A falta de clareza sobre 0 papel do repatriado na área e sobre o planejamento da empresa em relação ao repatriado dificulta a aceitação dele pelo restante da equipe que, muitas vezes, é incapaz de entender e aceitar as mudanças propostas pelo executivo.

“Os problemas são como os outros os vêem, aceitação e confiança dos colegas que não estão preparados para as mudanças trazidas pelo expatriado. E curto tempo para readaptação" (M 5).

"porque a equipe também acaba não se acostumando com o repatriado, porque 0 expatriado normalmente vem com ideias revolucionárias, porque são pessoas que olharam, viram, viveram coisas ao longo do mundo, e voltam ao Brasil com ideias de revolução, de cortar processos, de minimizar coisas e às vezes isso é um choque para equipe..." (M 7).

Embora reconheçam a importância da designação de um mentor como um canal de comunicação, esta é uma prática pouco utilizada; apenas três entrevistados relataram que os executivos têm um mentor durante a expatriação.

Em relação ao apoio à família, na maioria das empresas, pode-se dizer que se limita ao suporte logístico nos primeiros meses subsequentes à repatriação, como trazer a mudança para o B rasil e pagar aluguel, hotel ou auxílio moradia, práticas que mais podem ser consideradas como benefícios do que como apoio no sentido de ajudar a adaptação pessoal ou cultural. E quanto à adaptação e apoio psicológico ao repatriado e à família no retorno, a única ação descrita nesse sentido pelas empresas da amostra refere-se à educação dos filhos. Duas empresas pagam a escola durante um período depois do retorno, uma paga aulas de reforço para as crianças que apresentam dificuldades na escola e uma 
outra, aulas particulares para crianças que não foram alfabetizadas em português. Portanto, as ações em relação à adaptação da família no retorno são bastante reduzidas, mesmo que seja de conhecimento das empresas, que as famílias enfrentam problemas na volta, como a dificuldade do cônjuge em retornar ao mercado de trabal ho e o choque cultural reverso, que poderia ser minimizado por meio de treinamento e orientação.

A lém disso, pôde ser percebido que as empresas não possuem ações para que os executivos desenvolvam expectativas realistas quanto ao novo padrão de vida, perda de status e autonomia e 0 novo posto de trabal ho que ocupará, práticas ressaltadas por Harvey (1989) e Lazarova e Caligiuri (2001) como importantes para um bom processo de repatriação. Novamente, os entrevistados demonstraram reconhecer os problemas, mas não souberam relatar nenhuma ação para que essas expectativas pudessem ser mais bem gerenciadas.

Quanto ao índice de retenção dos executivos, que seria indicativo do sucesso na repatriação e, portanto, provavelmente decorrente das práticas adotadas, a maioria dos entrevistados (14) relatou que apenas 'cerca de uns 5\%' deixam a empresa nos dois anos subsequentes à repatriação; os demais, no entanto, não souberam dizer nem um número aproximado. Mas pode ser observado que não há a preocupação de fazer levantamentos mais detalhados sobre esse índice, o que sugere falta de preocupação com a retenção desses executivos.

Os entrevistados das empresas brasileiras revelaram que apesar de a internacionalização dessas empresas ter começado aproximadamente em 2000, a intensificação das expatriações aconteceu a partir de 2006 e, por esse motivo, o número de repatriados que as empresas brasileiras recebem por ano, atualmente, é baixo. A partir de 2010 é esperado que as empresas brasileiras tenham um volume maior de repatriações e estima-se que não haverá oportunidades profissionais tão atraentes para todos os repatriados como há atualmente, o que pode diminuir o índice de retenção. A liado ao baixo número de repatriações anuais hoje existentes, os entrevistados comentaram que as empresas brasileiras estão em fase de expansão ${ }^{1}$, conseguindo oferecer boas oportunidades profissionais aos executivos repatriados, o que também explica 0 al to índice de retenção dos executivos que possuem vivência internacional. A demais, os entrevistados afirmam que o brasileiro, em geral, se adapta facilmente tanto na ida quanto na volta e, portanto, a repatriação seria um processo relativamente tranquilo. Há também aqueles que pensam que a adaptação é um processo que deve, necessariamente, acontecer.

“Não enfrentam problemas. Nem para ir nem para voltar. Houve um executivo que ficou nove anos fora e disse que quando colocou o pé no aeroporto já estava adaptado novamente" (B 8).

"Logo no retorno, tem uma preocupação maior, a pessoa começa a buscar casa de novo, no começo você vê que a preocupação é maior, mas logo você se acostuma de novo, depois de um tempo já está bem" (B 1).

"A cho que não tem que ficar com frescura, não, voltou, tem que se adaptar" (M 3).

Os entrevistados das empresas multinacionais relataram que, apesar da maior parte dos executivos repatriados continuarem na empresa, muitos deles nem chegam a ser repatriados, pois são localizados no país da expatriação. Segundo eles, os executivos escolhem tornar-se funcionários locais em países em que as oportunidades profissionais na empresa são melhores do que na unidade brasileira. No caso das empresas brasileiras, os entrevistados relataram que, em geral, os executivos preferem retornar ao Brasil a se tornar um funcionário local, pois retornar ao B rasil significa retornar à matriz, onde estão as melhores oportunidades de crescimento profissional na empresa. Como se pode observar, tanto os entrevistados das brasileiras quanto os das estrangeiras pareciam ter explicações que justificariam a ausência de muitas das práticas desejáveis para um melhor processo de repatriação.

Os principais motivos apontados pelos entrevistados para a saída de executivos repatriados são: (i) melhores oportunidades, devido à valorização da experiência internacional pelo mercado; (ii) a empresa não corresponder à expectativa do repatriado, em relação à promoção; (iii) o repatriado ter desejo de continuar a carreira internacional e não há possibilidade ou interesse da empresa em expatriá-Io novamente; e por fim, (iv) opção do repatriado por mudança de qualidade de vida e desejo de viver em cidades mais seguras que São Paulo. 
A comparação entre empresas brasileiras e estrangeiras não mostra diferenças muito significativas entre as práticas adotadas. Em termos de números de práticas adotadas, duas M NCs brasileiras tem 13; uma estrangeira tem 12; duas estrangeiras e uma brasileira tem 11 e uma brasileira e uma estrangeira tem 10, por exemplo; e o restante também parece estar equilibrado em termos de número de práticas. $\checkmark$ ale ressaltar, no entanto, que o número de práticas não significa que o processo de repatriação esteja bem estruturado e funcionando de modo a atender às necessidades do repatriado. U ma análise mais detalhada precisa ser realizada. Nesse sentido, as empresas B6, M 5 e M 6 parecem ter processos mais bem elaborados, pois contam com meios mais específicos de comunicação com 0 expatriado (tel efonemas e viagens do responsável para os locais onde moram os expatriados), tem planejamento formal de carreira (nos casos da M 5 e M 6), tentam oferecer promoção no retorno e buscam ter contato mais próximo com o expatriado, quer seja com o responsável, quer seja com o gestor ou com um mentor. A análise mostra que as MNCs estrangeiras tendem a ter processos de planejamento de carreira mais estruturados, provavelmente porque estão enviando os executivos brasileiros em processo sucessório para outros países, o que foi confirmado pelos entrevistados.

\section{DISCUSSÃO DOS RESULTADOS}

Os resultados da pesquisa mostram que as principais políticas e práticas de recursos humanos para a repatriação, apresentadas na literatura e encontradas nas empresas pesquisadas, são estas: manter 0 executivo informado sobre as mudanças que ocorrem na organização durante a expatriação, pagamentos de viagens ao país de origem durante a expatriação, verba para realização da mudança, apoio durante o processo de expatriação e recolocação do executivo no mercado de trabalho, se não houver um posto apropriado no retorno. No entanto, assim como encontrado por Harvey (1989) e Lazarova e Caligiuri (2001), algumas dessas políticas e práticas são adotadas apenas parcialmente, como, por exemplo, a comunicação, deficiente na maioria das empresas.

Pode-se dizer que o processo de repatriação é ainda negligenciado pelas empresas. A o contrário da expatriação, em que há espaço para o futuro expatriado negociar benefícios e dialogar com a empresa, na repatriação esse espaço desaparece. 0 número de empresas da amostra que possuem políticas estabelecidas para a repatriação é bastante reduzido. Em todas, observou-se que, apesar de os responsáveis pelo processo estarem cientes dos problemas enfrentados pelos repatriados, não há uma política definida e documentada para a repatriação de executivos.

Conforme comentado, os entrevistados justificam essa diferença de atenção destinada ao processo de repatriação, dizendo que a empresa está focada em enviar executivos para o exterior e não em repatriar, ou que o número de repatriados é muito baixo, ou que os brasileiros não têm dificuldades de adaptação nem na expatriação nem no retorno ao B rasil, o que claramente mostra uma miopia da área de Recursos Humanos e dos gestores em geral, ao não saber identificar o que a empresa está perdendo em termos de conhecimentos e competências, quando perde um executivo com experiência internacional.

Em relação ao treinamento dado para o repatriado por quatro empresas sobre as mudanças em relação a planos de saúde, vale-refeição, planos de previdência etc., pode-se considerar que se trata de uma atualização do executivo sobre a realidade organizacional, mas que não o prepara para uma adaptação cultural, após longo período fora do país, que o faça sentir-se menos 'estrangeiro' em sua própria terra, uma vez que sua identidade, valores e visão de mundo possa ter mudado consideravelmente.

Os dados mostram que a maioria das empresas (15) não se preocupa com o planejamento da carreira dos repatriados, o que também é apontado pela literatura. Kraimer, Shaffer e Bolino (2009) encontraram que apenas $17 \%$ dos repatriados são promovidos e pesquisa da Fundação Dom Cabral encontrou que apenas 13\% recebem promoção no retorno; que $80 \%$ não têm a experiência internacional valorizada como se deveria e que $60 \%$ não têm garantia de emprego no retorno 
(Giardino, 2006). A falta de perspectiva de promoção e valorização no retorno pode ser uma das razões pelas quais o executivo não vê a expatriação como uma possibilidade de desenvolvimento profissional, como afirmado pelos entrevistados. Os expatriados podem estar, de fato, desenvolvendo carreiras internacionais sem fronteiras, conforme colocam Stahl et al. (2009), em parte porque percebem que a experiência internacional é valorizada por outras empresas e, em parte, porque não se sentem suficientemente val orizados na própria empresa.

Chama a atenção, também, o fato de que os responsáveis pelo processo de expatriação e repatriação nas empresas, com exceção de dois deles, não tiveram uma experiência de expatriação. A credita-se que ex-expatriados teriam mais condições de conhecer e entender as expectativas dos executivos em relação às empresas, às necessidades e aos problemas que os expatriados e sua família poderão enfrentar na ida e no retorno, bem como a 'dependência' que desenvolvem. Conforme coloca Freitas (2005), muitos dos responsáveis pelo processo de expatriação nunca saíram do país nem como turistas e, portanto, não possuem uma preparação intercultural nem conhecem o que existe além da percepção do fascínio de uma expatriação, o que pode resultar em uma visão simplista do processo.

As ações relativas à adaptação da família também são restritas e de ordem bastante operacional. $\mathrm{Na}$ expatriação ainda se observa um esforço um pouco maior com o oferecimento de curso de línguas e até o pagamento de cursos de especialização para o cônjuge; na volta, porém, 0 auxílio é bem menor e não há auxílio para o cônjuge se recolocar no mercado de trabalho, por exemplo, após um longo período afastado, o que é sempre problemático.

0 alto índice de retenção dos repatriados relatado pelas empresas não significa que tenham um processo de repatriação que atenda às necessidades e expectativas dos repatriados, e que os executivos não tenham problemas de adaptação no retorno nem significa o sucesso do processo repatriação. Repatriar um executivo e subutilizar as experiências adquiridas por ele na expatriação e ter um funcionário trabalhando insatisfeito com a empresa, com certeza não significa uma vitória nem para a empresa nem para o executivo repatriado.

A taxa de $95 \%$ de retenção dos repatriados deve ser analisada com cautela. Os dados obtidos nas entrevistas não devem ser desacreditados, mas dois fatores sugerem que o número dado pelos entrevistados pode não corresponder, de fato, à realidade. 0 primeiro fator é o relato dos próprios entrevistados de que a área responsável pelo processo não acompanha os executivos depois que estes retornam ao B rasil. Como dito anteriormente, os entrevistados não souberam responder ao certo nem quantos executivos são repatriados por ano, o que reforça a ideia de que as áreas realmente não acompanham esses executivos depois do retorno e, por isso, pode-se pensar que dificilmente as áreas responsáveis pelo processo têm 0 número exato de repatriados que deixa a empresa nos anos subsequentes à repatriação. Portanto, a estimativa de $95 \%$ de retenção não parece ser baseada em levantamentos quantitativos. 0 segundo fator são os resultados encontrados pela Fundação Dom Cabral em que $20 \%$ dos repatriados deixam a empresa no primeiro ano e $40 \%$ no segundo ano após retornar ao B rasil (Tanure, Cyrino, \& Penido, 2005).

A demais, apesar de ter sido encontrado um alto índice de retenção dos repatriados, as empresas não possuem uma política de retenção desses executivos e, portanto, outros fatores podem ser responsáveis pela elevada taxa de retenção de repatriados encontrada na pesquisa. Freitas (2005) argumenta que 0 aumento do desemprego em vários países e a faixa etária dos executivos, vista como impedimento para novas contratações, podem ser fatores que levam os executivos a aceitar a expatriação, a fim de preservar o emprego. Pode-se pensar que, talvez essas também sejam razões para que os executivos continuem na empresa na repatriação, mesmo que tenham problemas de adaptação ou que não tenham as suas expectativas profissionais atendidas pela empresa.

No caso das empresas brasileiras, fatores como as al tas taxas de crescimento das empresas, relatadas pelos entrevistados, e o fato de os repatriados retornarem para a matriz, que em geral tem melhores oportunidades profissionais que as subsidiárias, podem também explicar a retenção dos repatriados. Nas empresas multinacionais de capital estrangeiro, quando as expatriações acontecem para 0 desenvolvimento do profissional, o executivo tem claro que está no processo sucessório de outro 
profissional e, portanto, a perspectiva de uma promoção futura pode ser 0 fator que explique 0 alto índice de retenção encontrado. Portanto o desenvolvimento profissional parece, sim, em alguns casos, ser uma das razões pelas quais o executivo aceita a expatriação e permanece na empresa na repatriação.

\section{CONSIDERAÇõES FINAIS}

A pesquisa buscou levantar as políticas e práticas de recursos humanos utilizadas pelas empresas no B rasil para garantir o sucesso do processo de repatriação e retenção dos repatriados. Percebeu-se que as ações das empresas no processo de repatriação não são ações estratégicas e ainda estão mais relacionadas a oferecer um apoio operacional ao repatriado. Observou-se que as políticas e práticas que poderiam solucionar ou minimizar os principais problemas que os repatriados enfrentam não são adotadas. Problemas como perda de autonomia, frustração em relação ao cargo ocupado no retorno, ter a sua experiência ignorada pelo gestor e pelos colegas de trabalho, além da difícil readaptação familiar, recebem atenção insuficiente das empresas. E ainda que todos os entrevistados tenham declarado ter consciência de que os repatriados enfrentam esses problemas e de que ter um processo bem estruturado é importante para o sucesso da repatriação, parece que não há disposição suficiente para se elaborar políticas e práticas efetivas para o retorno e retenção desses executivos.

A comunicação clara e eficaz e o planejamento da carreira desses executivos parecem ser essenciais para a permanência na empresa. Conforme declarado pelos entrevistados e apontado pela literatura (Shaffer, Harrison, \& Gilley, 1999), a expatriação ocorre por vários motivos: desenvolvimento profissional, levar expertise e o modelo de gestão da matriz para a subsidiária, desenvolvimento de novos negócios, manter a integração e a cultura da matriz nas subsidiárias e, às vezes, para atender a necessidades urgentes do negócio. Observa-se, portanto, que se trata de objetivos estratégicos importantes e que o expatriado é o ator responsável pela implementação de um objetivo específico. Portanto, planejar e estruturar a ida e o retorno desses executivos sob todos os aspectos envolvidos também deveria ser um processo de importância estratégica.

A parentemente outros fatores são relevantes para garantir o al to índice de retenção dos repatriados nas empresas da amostra, mas pesquisas futuras são necessárias para se levantar porque, mesmo sem adotar as principais políticas e práticas, sem ter um processo de repatriação estruturado e sem ter um planejamento da carreira dos repatriados, as empresas brasileiras apresentam índices tão altos de retenção dos repatriados. 0 sucesso da repatriação, a adaptação do repatriado à empresa e a adaptação do repatriado e da família ao país e à vida social e familiar parecem depender muito mais das características dos brasileiros, do esforço pessoal dos repatriados e dos seus familiares e das características do mercado de trabalho no Brasil, do que do suporte organizacional oferecido.

A credita-se que entre as contribuições desta pesquisa, vale mencionar que, além de ser a primeira realizada no Brasil, também trouxe inovações em relação às duas pesquisas anteriores que investigaram as práticas sob a perspectiva da organização, a de Harvey (1989) e de Lazarova e Caligiuri (2001). N esse sentido, esta pesquisa detal hou os meios pelos quais as práticas são atualmente instrumentalizadas, que surgiram dos relatos dos entrevistados e que são apresentados na Tabela 1. M ostrou também que, embora os diversos estudos conduzidos com repatriados posteriormente aos de Harvey (1989) e de Lazarova e Caligiuri (2001), como os de Linehan e Scullion (2002) e de M ila e Cerdin (2007), entre outros, tenham mostrado a insatisfação com as práticas organizacionais de repatriação, as empresas não parecem ter dedicado maior atenção a esse processo, afora nos casos em que a expatriação se refere a um processo sucessório. Isto reforça a ideia de que, de fato, a repatriação não é, ainda, percebida como estratégica.

Quanto a pesquisas futuras, a maior parte dos trabalhos sobre o tema estuda o processo de expatriação e repatriação de executivos e, portanto estudos sobre carreira internacional de funcionários de níveis não executivos são raros. As empresas brasileiras de negócios de engenharia e construção 
relataram que expatriam também funcionários de nível operacional e que esses possuem um pacote de benefícios bastante inferior ao dos executivos expatriados; pesquisas futuras sobre as políticas de recursos humanos para postos não executivos podem contribuir para esse campo de estudo.

\section{Artigo recebido em 28.12.2009. A provado em 16.08.2010.}

\section{NOTA}

\footnotetext{
${ }^{1}$ A s entrevistas foram realizadas em agosto e início de setembro de 2008, ou seja, antes do agravamento da crise econômica mundial.
}

\section{REFERÊNCIAS BIBLIOGRÁFICAS}

Bardin, L. (2008). Análise de conteúdo. Lisboa: Edições 70.

Black, J. S., \& Gregersen, H. B. (1999). The right way to manage expats. Harvard Business Review, $77(2), 52-63$.

Costa, J. E. (2008, setembro). 0 desafio de crescer. Você S/A Exame, Edição Especial, pp. 38-42.

Editora A bril. (2008). Revista Exame: melhores e maiores - as 500 maiores empresas do país. São Paulo, SP: A utor.

Freitas, M. E. (2000b). Como vivem os executivos expatriados e suas famílias? (R elatório de Pesquisa $N^{\circ}$ 7). São Paulo, SP, N úcleo de Pesquisa e Publicação, Escola de A dministração de Empresas da Fundação G etúlio V argas.

Freitas, M. E. (2000a, setembro). Vida de executivo expatriado - a festa vestida de riso ou de choro. Anais do Encontro Nacional da Associação Nacional de Pós-Graduação e Pesquisa em Administração, Florianópolis, SC, B rasil, 24.

Freitas, M. E. (2005). Executivos brasileiros expatriados na França: uma contribuição aos estudos organizacionais interculturais. M onografia para acesso ao cargo de professor titular, Fundação Getúlio V argas, São Paulo, SP, B rasil.

Giardino, A. (2006, agosto 21). 0 difícil regresso dos que são transferidos para fora do país. Valor Econômico, Caderno Eu e Investimento/ Carreira, p. 6.

Godoi, C. K., \& Mattos, P. L. C. L. (2006). Entrevista qual itativa: instrumento de pesquisa e evento dialógico. In C. K. Godoi, R. B. M ello, \& A. B. Silva (Orgs.), Pesquisa qualitativa em estudos organizacionais (pp. 301-323). São Paulo: Saraiva.

Gonçalves, G. A., \& Miura, I. K. (2002, setembro). Executivo expatriado: fatores que afetam 0 ajustamento internacional. Anais do Encontro Nacional da Associação Nacional de PósGraduação e P esquisa em Administração, Salvador, BA, Brasil, 26.

Harvey, M. G. (1982). The other side of foreign assignments: dealing with the repatriation dilemma. The Columbia J ournal of World Business, 17(1), 53-59.

Harvey, M. G. (1989). Repatriation of corporate executives: an empirical study. Journal of International Business Studies, 20(1), 131-144. 
K raimer, M. L., Shaffer, M. A., \& Bolino, M. C. (2009). The influence of expatriate and repatriate experiences on career advancement and repatriate retention. Human Resource Management, 48(1), 27-47.

Lazarova, M., \& Caligiuri, P. (2001). Retaining repatriates: the role of organizational support practices. J ournal of world business, 36(4), 389-401.

Lazarova, M ., \& Cerdin, J. L. (2007). Revisiting repatriation concerns: organizational support versus career and contextual influence. J ournal of International Business Studies, 38(3), 404-429.

Lee, H. W., \& Liu, C. H. (2006). The determinants of repatriate turnover intentions: an empirical analysis. International J ournal of M anagement, 23(4), 751-762.

Linehan, M., \& Scullion, H. (2002). Repatriation of European female corporate executives: an empirical study. International J ournal of Human Resource M anagement, 13(2), 254-267.

Nelson, J. (2005). The benefits of a formal repatriation program for the organization and the expatriate. E mployee Benefit News, 19(14), 20.

Nunes, L. H., Vasconcelos, I. F. G., \& Jaussaud, J. (2008). Expatriação de executivos [Coleção Debates em A dministração]. São Paulo: Thomson.

Pereira, N . A . F., Pimentel, R., \& K ato, H. T. (2004, setembro). Expatriação e estratégia internacional: o papel da família como fator de equilíbrio na adaptação do expatriado. Anais do Encontro Nacional da Associação Nacional de Pós-Graduação e Pesquisa em Administração, Curitiba, PR, Brasil, 28.

Scullion, H. (1994). Staffing policies and strategic control in British multinationals. International Studies of M anagement and O rganization, 4(3), 18-35.

Shaffer, M . A ., Harrison, D. A ., \& Gilley, K. M . (1999). Dimensions, determinants, and differences in the expatriate adjustment process. J ournal of International Business Studies, 30(3), 557-581.

Stahl, G., Chua, C., Caligiuri, P., Cerdin, J ., \& Taniguchi, M . (2009). Predictors of turnover intentions in learning-driven and demand-driven international assignments: the role of repatriation concerns, satisfaction with company support and perceived career advancement opportunities. Human Resource M anagement, 48(1), 89-109.

Stevens, M. J., Oddou, G., Furuya, N., \& Bird, A. (2006). HR factors affecting repatriate job satisfaction and job attachment for Japanese managers. International Journal of Human Resource M anagement, 17(5), 831-841.

Stroh, L. K., Gregersen, H. B., \& Black, J. S. (1998). Closing the gap: expectations versus reality among repatriates. J ournal of World Business, 33(2), 111-124.

Suutari, V., \& Brewster, C. (2003). Repatriation: empirical evidence from a longitudinal study of careers and expectations among Finnish expatriates. International J ournal of Human Resource Management, 14(7), 1132-1151.

Tanure, B., Cyrino, A. B., \& Penido, E. (2005, junho 20). Seus executivos estão prontos para comandar lá fora? Valor E conômico, Caderno Eu e Investimento/ Carreira, p. 6.

Tanure, B., \& Duarte, R. G. (2007). 0 impacto da diversidade cultural na gestão internacional. In B. Tanure \& R. Duarte (Orgs.), G estão internacional (pp. 193-220). São Paulo: Saraiva.

Thomas, D. C., \& Lazarova, M. B. (2006). Expatriate adjustment and performance: a critical review. In G. K. Stahl \& I. Björkman (Eds.), Handbook of Research in International H uman Resource M anagemen (pp. 249-264). Cheltenham: Edward Elgar. 
Tung, R. L. (1988). Career issues in international assignments. The Academy of Management Executive, 2(3), 241-244.

Tung, R. L. (1998). A merican expatriates abroad: from neophytes to cosmopolitans. J ournal of World Busines, 33(2), 125-144.

Witting-Berman, U., \& B eutell, N. (2009). International assignments and the career management of repatriates: the boundaryless career concept. International J ournal of Management, 26(1), 7788. 